\title{
Modification of Strength Training Programs in Handball Players and its Influence on Power During the Competitive Period
}

\author{
by \\ Michal Spieszny1, Mateusz Zubik
}

\begin{abstract}
A high level of muscle power is necessary for the effective use of technique during handball competitions. The presented research concentrated on comparing the effectiveness of two training modes directed towards the development of muscle power - plyometric and traditional strength training. Furthermore, we evaluated whether resistance training performed twice a week was sufficient to guarantee an increase in muscle power of handball players. We also investigated whether strength training designed according to the "waving" model (one training session per week oriented towards the development of maximal strength and one towards the development of power) was sufficient to increase muscle power in handball players. The study included 28 professional handball players who were divided into 3 groups: Group 1 subjected to additional strength training (8 individuals), Group 2 subjected to traditional plyometric training (8 individuals) and Group 3 following standard training (12 individuals). Research was conducted at the beginning and at the end of the 1st round of competitions and consisted of the following measurements: CMJ (countermovement jump) and SJ (squat jump), a 10-s trial on a cycle-ergometer and ball-throwing velocity. Analysis of the results showed that both the plyometric and strength training programs induced a statistically significant increase in jumping height and generated power during the CMJ. The group subjected to additional strength training achieved greater increases in CMJ power than the group carrying out plyometric training, which in case of the CMJ peak power turned out to be statistically significant $(p<0.05)$. Different results were obtained when studying changes in the flight speed of the thrown ball; the group undergoing plyometric training registered minor increases (significant in the standing throw ), and there were decreases in the flight speed of the thrown ball (significant in the leaning back throw) in the group following the traditional strength training program.
\end{abstract}

Key words: handball, strength training, plyometric training, lower limb strength, ball-throwing velocity.

\section{Introduction}

Handball is a very dynamic sports discipline, in which short actions lasting no longer than 10-20 seconds dominate. Over the course of the competition, repeated efforts at high intensity and varying duration occur, which results in the playing time to be approximately $30-35 \%$ in the anaerobic zone. The applied techniques (passes, throws, jumps, starts, changes of running direction), as well as proper technical and tactical behaviours (e.g., ball handling, individual defensive actions, direct contact with opponents, etc.) often require the player to develop high

values of power in a very short time. This means that the effectiveness of a technique in sports competition is largely dependent on the level of competitor's anaerobic power (Gorostiaga et al., 2005; Povoas at al., 2012; Thorlund et al., 2008; Wagner et al., 2014). The ability to develop high anaerobic power of the upper limbs and trunk is also associated with the ability to implement high speed to the ball during a throw, which many researchers consider to be a key offensive factor affecting the performance of a player during the game (Debanne and Laffaye, 2011，2013;

1 - Institute of Sports, University of Physical Education in Cracow, Poland.

2 - Institute of Physical Education and Sports, AGH - University of Science and Technology, Poland. 
Gorostiaga et al., 2006; Marques and GonzalezBadillo, 2006).

It seems that the best way to improve the strength of a handball player is to use plyometric exercises (Gabbett et al., 2008; Young et al., 2002). Regular use of these exercises increases muscle tolerance to significant eccentric loads and allows for better use of the stretch shortening cycle (SSC). However, this type of training is considered controversial. Many studies confirm the effectiveness of plyometric exercises in increasing the strength and power of athletes. However, concern is raised by excessive overloading during such exercises, which may have adverse effects on the athlete's health, especially injuries to the joints, ligaments and muscles (Bowers et al., 2004; Zatsiorsky and Kraemer, 2006). In addition, studies on competitive athletes, which frequently perform jumps during training and competition (volleyball, basketball, etc.) indicate that the use of plyometric training does not significantly improve athletic performance (Carvalho et al., 1998). This may be due to the fact that for team players in volleyball, basketball or handball, performing jumps is a regular part of most training sessions, thus additional plyometric exercises may be an insufficient stimulus for the neuro-muscular system (Trajkovic at al., 2012). This raises the question about the legitimacy of using additional plyometric exercises in such team sports training.

It should also be noted that strength training produces other effects than those resulting from explosive resistance training. Depending on the value of the applied load, strength training may vary in its influence on the course of the strength-speed curve (Jones et al., 2001; Kawamori and Haff, 2004; McBridge et al., 2002). Training based on large loads increases the level of power (Fleck and Kraemer, 1997; Wilson et al., 1993). Training explosively with small-loads can increase the rate of force development (RDF) (Aagaard et al., 2002; Haff et al., 2005; Holtermann et al., 2007), thus, improving the power level at low resistance (Fleck and Kraemer, 1997; Wilson et al., 1993). It seems important that coaches understand the load extent to which athletic competitions take place in their specific discipline in order to develop muscular power of athletes with external resistance characteristics for that sport. Nonetheless, this is not always easy because power requirements often vary within a discipline. In handball, an athlete must generate significant power regarding both small (e.g., throws) and large (e.g. fighting for a position on the field, defence) external forces. Therefore, when designing a handball resistance training program, one cannot focus solely on power, bypassing maximal strength training.

To optimize the effectiveness of resistance training, it must be harmoniously integrated into the overall training program developed for a particular sport discipline (Bompa and Haff, 2009). Although muscle strength and power are extremely important in handball, they are not the only factors determining success in this sport. Basic handball training is directed at improving technical and tactical skills. The periodization of strength training in handball is an extremely important issue. Under the conditions of high motor demands placed on the athlete in competitive sports, it is necessary to carry out systematic strength training over the course of the entire annual training cycle. This is especially important in disciplines such as handball, where a classic division of the annual macrocycle takes place and the players participate in competitions all year round. During the competitive period, the task of the athlete is to maintain or even improve the level of muscular power and strength developed during the preparatory period. Developing a training program during this period is extremely difficult, as it must be sufficiently intense to stimulate improvements in motor abilities, while avoiding excess fatigue that could lead to overtraining (Silvestre et al., 2006). Due to weekly competitions, traditional or block training does not seem to be the logical choice. In such a case, specialists in training periodization propose the use of the non-linear "waving" pattern (Apel et al., 2011; Fleck, 2004; Prestes et al., 2009), which is characterized by continuous variation of training loads focused on different abilities (muscle mass, strength, power). This pattern has two variations: week-"waving" and day-"waving". In the first variation, the motor ability which is stressed changes on a weekly basis (we devote one week to each ability and then we move on to the next one) (Apel et al., 2011). In the second version, the change occurs after each or every other training session, but each ability is to be trained within one week (Fleck, 2004; Prestes et al., 2009). 
Another disputed issue concerns the amount of training sufficient to sustain the strength and power of the athlete. Is one training session per week sufficient to maintain the level of strength? Authors quoted by Zatsiorsky (1995) find that training twice a week is a good stimulus to maintain strength, but not enough for its improvement. As noted by Bomba and Haff (2009) in athletes who undertake strength training to improve performance in other activities, less training units should be sufficient to develop specific muscle functions. However, they must be realized in such a way that none of the aforementioned abilities will reach their maximum level.

Therefore, the main aim of this study was to compare the effectiveness of two types of resistance training (plyometric and traditional strength training) in developing power of handball players during the competitive period. The impact of these types of training on the speed of the ball during a throw towards the goal was also investigated. Moreover, the study aimed to determine whether resistance training sessions held twice a week were a sufficient stimulus to maintain and increase the speed and strength abilities of handball players. With regard to strength training, it was also evaluated whether the periodization of training using the pattern of day-"waving" would have a positive effect on the athletes' muscle power.

\section{Methods}

\section{Participants}

Twenty eight professional handball players participating in the $1^{\text {st }}$ and $2^{\text {nd }}$ Polish divisions took part in the research. They were all adults and had at least 6 years of training experience. The athletes participated in 3 handball-specific training units per week with duration of 90 minutes each. After consulting the coaches, it was found that the workouts were similar in volume, intensity and training methods in all the clubs. Moreover, the athletes participated in additional resistance training, of which frequency, nature and volume were adjusted to the needs of the experiment.

\section{Procedures}

The study was conducted during the competitive period - first round of the 2014/2015 season - from the beginning of September to the end of December, 2014.

The participants were divided into 3 groups: group 1 - performing additional strength training (8 individuals), group 2 - performing additional plyometric training (8 individuals), group 3 - following standard training (12 individuals).

Players assigned to Groups 1 and 2 belonged to different clubs and they all volunteered to perform additional resistance training. The standard training group consisted of athletes who did not participate in any additional resistance training sessions.

All handball players participating in the experiment were tested twice. The first measurements were conducted at the beginning of the first round of the season, while the final evaluations were carried out at the end of this round.

\section{The experiment}

The studied athletes were divided into three groups: two groups were subjected to additional power-oriented training and one followed standard training.

The first group performed two additional units of strength training lasting about 45 minutes each. The "wave" pattern of training periodization was used and that is why one training session was focused on maximum strength, while the other was aimed at developing power. The training protocol focused on maximal strength was based on such exercises as the barbell squat, the deadlift and the bench press. The resistance was individualized in such a manner that each athlete could perform 3 to 6 repetitions of the exercise in 3-4 sets. The training protocol directed at the development of power included the following exercises: barbell jump squats, the clean and jerk, a dynamic bench press. The number of repetitions in particular sets ranged from 3 to 6 performed within 3-4 sets. In both groups the training loads increased progressively throughout the experiment, changing the intensity as well as the number of sets and in accordance with standard periodization procedures.

The second group consisted of athletes from one of the clubs who performed about 30-40 minutes of additional plyometric training twice a week. Plyometric training was based on such exercises as various kinds of two-handed medicine ball throws, jumping over obstacles in 
different directions, jumping over hurdles, drop jumps, skipping and multi-jumps. The number of sets varied from 3 to 4 , while each set consisted of 5 to 10 exercises.

Players included in the third group participated in regular club training sessions only.

\section{Evaluations}

The following variables were considered in the research: body height and body mass, vertical jump height on a force plate (height, maximal and relative power of the countermovement jump (CMJ) and squat jump (SJ)), maximal and relative power of the lower limbs evaluated using a 10-s cycle-ergometer sprint test (Vandewalle et al., 1985) and the flight speed of a ball thrown towards the goal from a standing, jumping and running position.

\section{Statistical analysis}

Data are presented as arithmetic means. To determine the level of significance of changes within the tested variables, the Student's t-test or the Wilcoxon signed rank test was used, depending on the results of the normalization test of the analysed variables. One-way ANOVA was used to determine the level of significance of differences in mean increases between the groups. To better visualize the dynamics of changes in the analysed motor abilities, the percentage increase rate was calculated for each of them according to the following formula:

$$
\mathrm{W}_{\%}=\left(\left(\mathrm{X}_{\mathrm{K}}-\mathrm{X}_{\mathrm{P}}\right) / \mathrm{X}_{\mathrm{k}}\right) \times 100 \%
$$

$\left(X_{k}-\right.$ final value of the studied variable, $X_{p}-$ baseline value of the studied variable).

\section{Results}

During the competitive period, both groups performing additional strength and plyometric training recorded statistically significant increases in particular variables of the counter-movement jump (CMJ). It should be noted that jump height increases were similar in both groups, yet with regard to maximum and relative power of the $\mathrm{CMJ}$, the strength training group presented significantly larger increases compared to the plyometric training group, and difference in CMJ maximum power values was statistically significant (Table 3).

Increases in SJ height were similar in all three groups, however, the only statistically significant improvement was observed for the group performing plyometric training. Nevertheless, none of the studied groups recorded a significant increase in maximum or relative power of the SJ.

\begin{tabular}{|c|c|c|c|c|c|c|}
\hline & \multicolumn{3}{|c|}{ Description of the study groups } & \multicolumn{2}{|c|}{ Table1 } & \multirow[b]{2}{*}{$\begin{array}{l}\text { Body } \\
\text { mass } \\
2(\mathrm{~kg})\end{array}$} \\
\hline & $\begin{array}{l}\text { Group } \\
\text { size }\end{array}$ & $\begin{array}{l}\text { Body height } \\
\qquad(\mathrm{cm})\end{array}$ & $\begin{array}{l}\text { Age } \\
\text { (years) }\end{array}$ & $\begin{array}{l}\text { Training } \\
\text { experience } \\
\text { (years) }\end{array}$ & $\begin{array}{l}\text { Body } \\
\text { mass } \\
1(\mathrm{~kg})\end{array}$ & \\
\hline $\begin{array}{l}\text { Group } 1 \\
\text { (strength training) }\end{array}$ & 8 & $183.1 \pm 4.18$ & $23.1 \pm 2.53$ & $9.9 \pm 3.18$ & 86.04 & 86.25 \\
\hline $\begin{array}{l}\text { Group } 2 \\
\text { (plyometric training) }\end{array}$ & 8 & $183 \pm 5.94$ & $21.1 \pm 2.17$ & $10.4 \pm 1.92$ & 88.69 & 87.24 \\
\hline $\begin{array}{l}\text { Group } 3 \\
\text { (standard training) }\end{array}$ & 12 & $182.7 \pm 5.75$ & $23 \pm 3.05$ & $11.2 \pm 2.59$ & 88.73 & 88.86 \\
\hline $\begin{array}{r}\text { Body me } \\
\text { Body }\end{array}$ & $\begin{array}{l}\text { ody mas } \\
\text { - bodyr }\end{array}$ & $\begin{array}{l}\text { it the beginnt } \\
\text { ss at the end }\end{array}$ & $\begin{array}{l}\text { ig of the co } \\
\text { ff the comp }\end{array}$ & $\begin{array}{l}\text { npetitive per } \\
\text { titive period }\end{array}$ & & \\
\hline
\end{tabular}


Table 2

Studied variables and size of their changes during the competitive period

\begin{tabular}{|c|c|c|c|c|c|c|c|c|c|}
\hline & \multicolumn{3}{|c|}{ Group 1} & \multicolumn{3}{|c|}{ Group 2} & \multicolumn{3}{|c|}{ Group 3} \\
\hline & $M I$ & M II & $\Delta_{I}$ & $M I$ & M II & $\Delta_{I I}$ & $M I$ & M II & $\Delta I I I$ \\
\hline CMJ height (m) & 0.488 & 0.520 & $0.032^{* *}$ & 0.455 & 0.482 & $0.027^{*}$ & 0.470 & 0.480 & 0.010 \\
\hline $\mathrm{CMJ}$ maximal power $(\mathrm{W})$ & 5.647 & 6.008 & $361^{* *}$ & 5.589 & 5.718 & $129^{*}$ & 5.634 & 5.731 & 97 \\
\hline $\mathrm{CMJ}$ relative power $(\mathrm{W} / \mathrm{kg})$ & 65.5 & 70.3 & $4.8^{* *}$ & 63.5 & 66.3 & $2.8^{*}$ & 64.1 & 64.9 & 0.8 \\
\hline SJ height (m) & 0.441 & 0.459 & 0.017 & 0.411 & 0.430 & $0.019^{*}$ & 0.427 & 0.444 & 0.016 \\
\hline SJ maximal power $(W)$ & 4949 & 4977 & 28 & 4644 & 4717 & 73 & 4689 & 4784 & 95 \\
\hline$S J$ relative power $(\mathrm{W} / \mathrm{kg})$ & 57.5 & 58.1 & 0.6 & 52.4 & 54.4 & 1.9 & 53.5 & 54 & 0.5 \\
\hline $\begin{array}{l}\text { Cycle-ergometer maximal power } \\
\text { (W) }\end{array}$ & 1016 & 1043 & 27 & 982 & 1021 & $39^{*}$ & 951 & 1022 & $71^{* *}$ \\
\hline $\begin{array}{l}\text { Cycle-ergometer relative power } \\
(\mathrm{W} / \mathrm{kg})\end{array}$ & 11.81 & 12.08 & 0.28 & 11.21 & 11.82 & $0.61^{*}$ & 10.93 & 11.58 & $0.65^{*}$ \\
\hline Standing throw $(\mathrm{km} / \mathrm{h})$ & 85.4 & 84.0 & -1.4 & 86.6 & 87.4 & $0.8^{*}$ & 82.2 & 77.5 & $-4.7^{*}$ \\
\hline Leaning back throw $(\mathrm{km} / \mathrm{h})$ & 91.7 & 88.9 & $-2.9^{*}$ & 89.8 & 91.2 & 1.4 & 97.2 & 82.5 & $-4.6^{*}$ \\
\hline Jumping throw $(\mathrm{km} / \mathrm{h})$ & 87.0 & 85.1 & -1.9 & 88.8 & 89.6 & 0.8 & 84.3 & 78.5 & $-5.7^{* *}$ \\
\hline
\end{tabular}

${ }^{*}$ statistically significant $(p<0.05)$

** statistically significant $(p<0.001)$

$\Delta_{I}$-difference in group 1 arithmetic means (increase or regression between the $1^{\text {st }}$ and $2^{\text {nd }}$ test) $\Delta_{I I}$-difference in group 2 arithmetic means (increase or regression between the $1^{\text {st }}$ and $2^{\text {nd }}$ test) $\Delta I I I$ - difference in group 3 arithmetic means (increase or regression between the $1^{\text {st }}$ and $2^{\text {nd }}$ test)

M I- first measurement

M II-second measurement

Table 3

Differences in increases in the studied variables; comparison between Groups 1 and 2.

\begin{tabular}{|c|c|c|}
\hline & & Group 1 \\
\hline \multirow{11}{*}{ 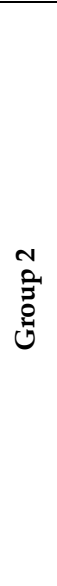 } & CMJ height (m) & 0.005 \\
\hline & $\mathrm{CMJ}$ maximal power $(\mathrm{W})$ & $232^{*}$ \\
\hline & $\mathrm{CMJ}$ relative power $(\mathrm{W} / \mathrm{kg})$ & 2 \\
\hline & SJ height (m) & -0.002 \\
\hline & SJ maximal power $(\mathrm{W})$ & -45 \\
\hline & $\mathrm{SJ}$ relative power $(\mathrm{W} / \mathrm{kg})$ & -1.3 \\
\hline & Cycle-ergometer maximal power (W) & -12 \\
\hline & Cycle-ergometer relative power $(\mathrm{W} / \mathrm{kg})$ & -0.33 \\
\hline & Standing throw $(\mathbf{k m} / \mathbf{h})$ & -2.2 \\
\hline & Leaning back throw $(\mathbf{k m} / \mathbf{h})$ & -4.3 \\
\hline & Jumping throw $(\mathbf{k m} / \mathbf{h})$ & -2.7 \\
\hline
\end{tabular}




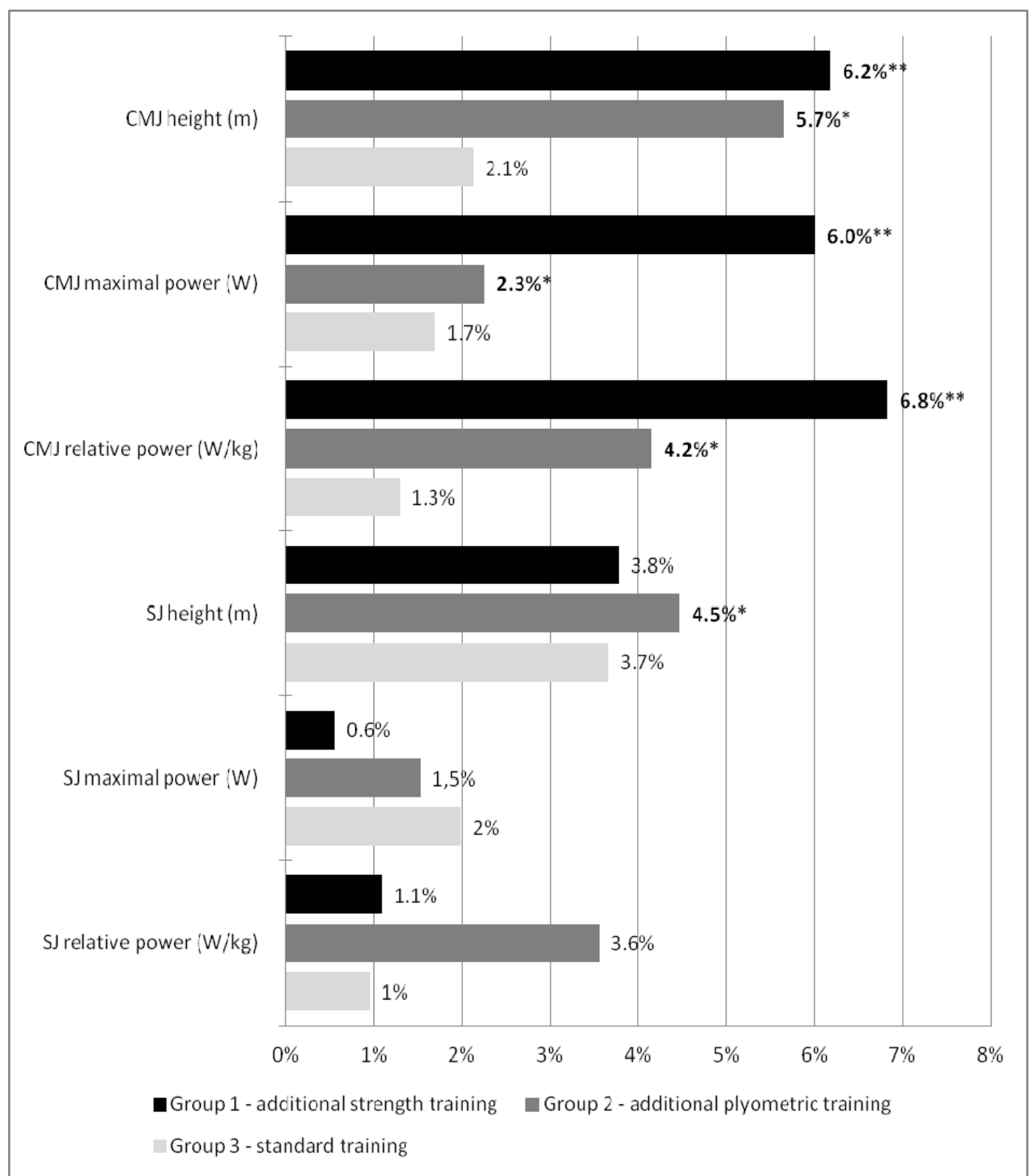

Figure 1

Percentage indicators of the increase in the studied variables and their statistical significance

${ }^{*}$ statistically significant $(p<0.05)$

** statistically significant $(p<0.001)$ 


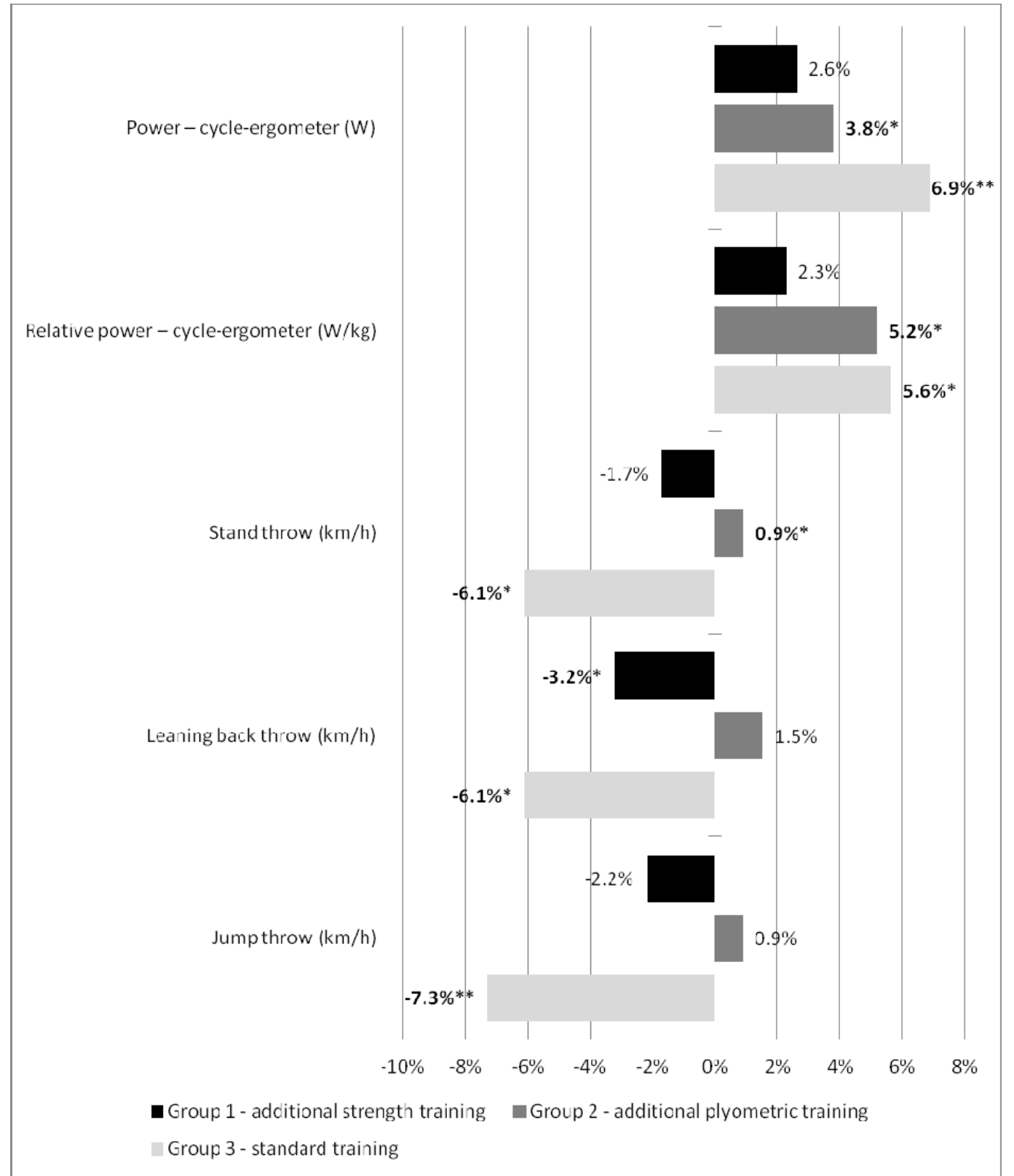

Figure 2

Percentage indicators of the increase in the studied variables and their statistical significance.

* statistically significant $(p<0.05)$

** statistically significant $(p<0.001)$ 
With respect to the results of the test on a cycle-ergometer, the group without any additional training programme was the one that achieved the greatest increases in both maximum and relative power. The smallest increase in this test was registered in athletes subjected to strength training. Regarding the flight speed of the thrown ball, only the group implementing additional plyometric training recorded improvements in this variable. The increase in the speed of the ball thrown from a standing position turned out to be of statistical significance. The strength training group recorded a decrease in this ability and in the leaning back throw, it turned out to be statistically significant. The largest regression was achieved by the group not subjected to any additional training, where the decreases were around 6-7\%, and each was statistically significant.

\section{Discussion}

One of the main aims of this study was to compare the effects of traditional resistance and plyometric training in handball players. To make such a comparison, the effectiveness of plyometric training was questioned. Particular concerns regarding application of plyometric exercises are related to the loads the athlete's motor system is subjected to during particular training units (Bowers et al., 2004; Zatsiorsky and Kraemer, 2006). Considering the large overloads that a handball player experiences during the competitive period, it seems unreasonable to subject him/her to additional loads, especially if their effectiveness is questionable (Carvalho et al., 1998; Trajkovic et al., 2012). It is also worth noting that in handball, many technical activities require maximum jumps (e.g. jump throw, jump to block), and thus, can be treated as jumping ability exercises. The question should be asked as to how many of these exercises an athlete executes during a training session, and if there is a need to supplement basic training sessions with plyometric exercises including jumps. The results of a study by Carvalho et al. (1998) show that the effect of plyometric exercises on jumping ability in athletes whose sport discipline-specific training is saturated with different types of jumps is strongly limited. The data presented in this work differ from the results of our own study, in which we demonstrated a significant increase in both jumping ability and power of the lower limbs in a group subjected to plyometric training. Similar findings have also been reported by other researchers (Cherif et al., 2012; Milic et al., 2008; Soundara and Pushparajan, 2010; Ziv and Lidor, 2010). Nevertheless, our research shows that wellplanned resistance exercises with the focus on maximal strength and power are more effective in developing muscle power, and at the same time, induce a comparable increase in jumping ability as plyometric exercises. These results are confirmed in another study in which the use of strength training alone or the use of an additional load during training directed at improving jumping ability has been shown to have positive effects on the development of power and jump height (Sheppard et al., 2008). Numerous reports have confirmed that this type of exercises should be used in training of handball players targeted at the development of power and jumping ability (Hermassi et al., 2011; Marques, 2010; Pauletto, 1993). However, we shall bear in mind that plyometric training using medicine balls proved to be more effective in developing muscle power manifested during a throw. Thus, this seems to be the best solution for developing muscle power of the upper limbs and shoulder girdle in handball players.

Apart from this main conclusion, several other interesting results were obtained during our experiment. In the half squat vertical jump test, a statistically significant increase was noted only for the height of the jump in the group subjected to additional plyometric training. However, this result was very similar to that for the group implementing additional strength training. All groups recorded non-significant increases in maximal and relative power of the SJ. The following question thus arises: Why didn't the exercises that had a very positive effect on jump height and power of the counter-movement jump produce similar effects in the squat jump variables? Why did plyometric exercises induce the greatest improvements in the SJ variables considering that in the SJ a dynamic stretch does not occur before the muscle contraction? This issue should be devoted more attention in future research. It is also important to determine whether the SJ test is a suitable tool for evaluation of the level of motor abilities in handball players.

A completely different distribution of 
results was obtained when analysing changes in the variables of the 10-s cycle-ergometer test. Interestingly, the highest increases were achieved by the group without any additional training. This illustrates how the dynamics of change in the power of the same muscle groups can vary depending on the form of movement in which the measurements are conducted. Therefore, there is a need to verify the test protocols applied in handball players, to ensure that the investigated forms of power are specific for this sport discipline.

Also of interest are the changes in flight speed of the ball thrown by the athletes registered during the competitive period. The results indicate some deficiencies in the resistance training programme used in Group 1. The exercises did not have a sufficient effect on the development of speed of the ball during a throw. Although a lower reduction was noted in Group 1 compared to Group 3, given the fact that another form of training provided power gains in this area, this was not a satisfactory result. In the plyometric training group, a statistically significant increase in the speed of the ball thrown was noted. The probable cause of this progress was the implementation of exercises with medicine balls performed by the athletes in this group. Despite the fact that the noted improvement was not significant, compared to the decreases noted for the other two groups, it can be considered positive, especially since the main factor taken into account during the design of the throwing exercises was the safety of the shoulder joint. It should be borne in mind that the overhead throw movement alone is associated with very high levels of overloading, which is often the cause of pain and serious injuries in sports requiring overhead throwing (Zazzali et al., 2007). The use of a heavy medicine ball in such exercises only increases the strain placed on this the shoulder joint. For this reason, in the training program used in this study we did not use onehanded throws with heavier balls, replacing them with general two-handed throwing exercises, which place a smaller strain on the shoulder joints (Zazzali et al., 2007). The included exercises induced increases in the ball flight speed, as demonstrated in the study by Hermassi et al. (2015). Similar strength training exercises in basketball players are recommended by Pauletto
(1993), as it is claimed that training which combines medicine ball throws and muscle strength exercises provides the best results in developing the power of the upper limbs. Pauletto (1993) mainly proposed exercises performed with both hands, which involved not only the upper limbs, but the whole kinetic chain. Most of his assumptions were made with reference to upper limb training in a group performing additional plyometric exercises.

Another test during the competitive period was conducted to check whether training sessions conducted twice a week constituted a sufficient stimulus to increase the level of speed and power of the handball players. In team sports, where strength training is used to improve performance in other sports actions, some authors recommend three sessions per week (Baechle, 1994; Schmidtbleicher, 1996), while others allow twice-weekly training sessions during the competitive period (Bompa and Haff, 2009; Pauletto, 1993). Zatsiorsky (1995) states that the minimum of two training sessions per week is necessary to maintain the level of muscle strength, but at least three are needed for strength enhancement. Bompa and Haff (2009) indicated that one workout per week was enough to sustain strength during the competitive period, once developed to high level during the preparatory period. Twice-weekly sessions should guarantee a minimum increase in these abilities. Our own research showed that training sessions performed twice a week resulted in increased muscle strength of athletes. It should be emphasized that the study involved athletes whose muscular power was an additional factor not directly related to the outcome of the competition. In athletes for whom muscle power is a key ability, this number of workouts may be insufficient. It is also important that the frequency of two training sessions per week is not considered standard but the minimum, which is the greatest compromise between handball-specific and strength training.

\section{Conclusions}

1. Implementing plyometric and strength training during the competitive period resulted in a significant increase in CMJ height as well as an increase in maximal and relative power during the $\mathrm{CMJ}$ in the studied athletes. However, greater increases in the height of the 
jump as well as maximal and relative CMJ power were noted in the group carrying out the traditional strength training programme.

2. Plyometric training had a positive influence on the development of abilities related to increasing speed of the ball during a goal throw. The implemented strength training did not guarantee to maintain the level of this ability during the considered period.
3. Training sessions held twice a week turned out to be sufficient for the development of muscle strength in the studied handball players.

4. Strength training designed according to the day "waving" pattern, consisting of one training session devoted to power and one to maximal strength, were effective in muscle power development of the lower limbs of the studied handball players.

\section{References}

Aagaard P, Simonsen EB, Andersen JL, Magnusson SP, Dyhre-Poulsen P. Increased rate of force development and neural drive of human skeletal muscle following resistance training. J Appl Physiol, 2002; 534: 613-623

Apel JM, Lacy RM, Kell RT. A comparison of traditional and weekly undulating periodized strength training programs with total volume and intensity equated. J Strength Cond Res, 2011; 25(3): 694-703

Baechle TR. Essentials of strength training and conditioning. Human Kinetics, Champaign; 1994

Bompa TO, Haff GG. Periodization: Theory and Methodology of Training. Human Kinetics, Champaign; 2009

Bowers EJ, Morgan DJ Proske U. Damage to the human quadriceps muscle from eccentric exercise and the training effect. J Sports Sci, 2004; 22(11-12): 1005-1014

Carvalho C, Marques A, Oliveira J, Morais FP. Evaluation of load intensity (60 vs 90\% 1HD) in plyometric training programs. (W:) Conference Book of International Conference on Weightlifting and Strength Training, Finland, 1998; 307-308

Cherif M, Said M, Chaatani S, Nejlaoui O, Gomri D, Abdallah A. The Effect of a combined high-intensity plyometric and speed training program on the running and jumping ability of male handball players. Asian J Sports Med, 2012; 3(1): 21-28

Debanne T, Laffaye G. Predicting the throwing velocity of the ball in handball with anthropometric variables and isotonic tests. J Sports Sci, 2011; 29(7): 705-713

Debanne T, Laffaye G. Coaches' beliefs and knowledge: Training programs used by French professional coaches to increase ball-throwing velocity in handball players. Int J Sports Sci Coach, 2013; 8(3): 557-569

Fleck SJ. Undulating periodization. (W:) E Kellis, IG Amiridis, IS Vrabes (red.): Conference on Strength Training, Greece, 2004; 14-17

Fleck SJ, Kraemer WJ. Designing resistance training programs. Human Kinetics, Champaign; 1997

Gabbett TJ, Kelly JN, Sheppard JM. Speed, change of direction speed, reactive agility of rugby league players. J Strength Cond Res, 2008; 22: 174-181

Gorostiaga EM, Granados C, Ibanez J, Izquierdo M. Differences in physical fitness and throwing velocity among elite and amateur male handball players. Int J Sports Med, 2005; 26: 225-232

Gorostiaga EM, Granados C, Ibanez J, Gonzalez-Badillo JJ, Izquierdo M. Effects of an entire season on physical fitness changes in elite male handball players. Med Sci Sports Exerc, 2006; 38: 357-366

Haff GG, Carlock JM, Hartman MJ, Kilgore JL, Kawamori N, Jackson JR, Morris RT, Sands WA, Stone MH. Force-time curve characteristics of dynamic and isometric muscle actions of elite woman Olympic weightlifters. J Strength Cond Res, 2005; 19: 741-748 
Hermassi S, Chelly MS, Tabka Z, Shephard RJ, Chamari K. Effects of 8-Week in-Season Upper and Lower Limb Heavy Resistance Training on The Peak Power, Throwing Velocity, and Sprint Performance of Elite Male Handball Players. J Strength Cond Res, 2011; 25(9): 2424-2433

Hermassi S, Van den Tillar R, Khlifa R, Chelly MS, Chamari K. Comparison of in-season-specific resistance vs. a regular throwing training program on throwing velocity, anthropometry and power performance in elite handball player. J Strength Cond Res, 2015; 29: 2105-2114

Holtermann A, Roeleveld K, Vereijken B, Ettema G. The effect of rate of force development on maximal force production: acute and training-related aspects. Eur J Appl Physiol, 2007; 99: 605-613

Jones K, Bishop P, Hunter G, Fleisig G. The effects of varying resistance-training loads on intermediate- and high-velocity-specific adaptations. J Strength Cond Res, 2001; 15: 349-356

Kawamori N, Haff GG. The optimal training load for the development of muscular power. J Strength Cond Res, 2004; 18: 675-684

Marques MC, Gonzlaez-Badillo JJ. In-season resistance training and detraining in professional team handball players. J Strength Cond Res, 2006; 20: 563-571

Marques MC. In-Season strength and power training for professional male team handball players. J Strength Cond Res, 2010; 32(6): 74-81

McBridge JM, Triplett-McBridge T, Davie A, Newton RU. The effect if heavy- vs. light-load jump squats on the development of strength, power and speed. J Strength Cond Res, 2002; 16: 75-82

Milic V, Nejic D, Kostic R. The effect of plyometric training on the explosive strength of leg muscles of volleyball players on single foot and two- foot takeoff jumps. Facta Univ Phys Educ Sport, 2008; 6(2): 169-179

Norkowski H. The intensity of handball competition in relation in the field. Physical Education and Sport, 2002; 46(2): 203-208

Pauletto B. Strength training for basketball. Human Kinetics, Champaign; 1993

Povoas SCA, Seabra AFT, Ascensao AAMR, Magalhaes J, Soares JMC, Rebelo ANC. Physical and physiological demands of elite team handball. J Strength Cond Res, 2012; 26(12): 3366-3376

Prestes J, Frollini AB, De Lima C, Donatto FF, Foschini D, de Marqueti RC, Figueira Jr A, Fleck SJ. Comparision between linear and daily undulating periodized resistance training to increase strength. $J$ Strength Cond Res, 2009; 23(9): 2437-2442

Schmidtbleicher D. Some neuromuscular aspects of human movements and the consequences for muscular rehabilitation. (W:) Proc. 14th Intern. Symp. Biomechanics in Sports, Funchal-Madera, Portugal, 1996; 120-129

Sheppard J, Hobson S, Barker M, Taylor K, Chapman D, McGuigan M, Newton R. The effect of training with accentuated eccentric load counter-movement jumps on strength and power characteristics of highperformance volleyball players. Int J Sports Sci Coach, 2008; 3: 355-363

Silvestre R, Kraemer WJ, West C, Judelson DA, Spiering BA, Vingren JL, Hatfield DL, Anderson JM, Maresh CM. Body composition and physical performance during a National Collegiate Athletic Association Division I men's soccer season. J Strength Cond Res, 2006; 20: 962-970

Soundara R, Pushparajan A. Effects of plyometric training on the development the vertical jump in volleyball players. J Phys Educ Spor, 2010; 28(3): 65-69

Thorlund JB, Michalsik LB, Madsen K, Aagaard P. Acute fatigue-induced changes in muscle mechanical properties and neuromuscular activity in elite handball players following a handball match. Scand J Med Sci Spor, 2008; 18(4): 462-472

Trajković N, Milanovic Z, Sporis G, Milic V, Stankovic R. The effects of 6 weeks of preseason skill-based conditioning on physical performance in male volleyball players. J Strength Cond Res, 2012; 26(6): 147580 
Vandewalle H, Pérès G, Heller J, Monod H. All out anaerobic capacity tests on cycle ergometers. A comparative study on men and women. Eur J Appl Physiol, 1985; 54(2): 222-229

Wagner H, Finkenzeller T, Würth S, von Duvillard SP. Individual and team performance in team-handball: a review. J Spotr Sci Med, 2014; 13: 808-816

Wilson GJ, Newton RU, Murphy AJ Humphries BJ. The optimal training load for the development of dynamic athletic performance. Med Sci Sports Exerc, 1993; 25: 1279-1286

Young WB, James R, Montgomery I. Is muscle power related to running speed with changes of direction? J Sports Med Phys Fitness, 2002; 42: 282-288

Zatsiorsky VM. Science and practice of strength training. Human Kinetics, Champaign; 1995

Zatsiorsky VM, Kraemer WJ. Practice and Science of Strength Training. Human Kinetics, Champaign; 2006

Zazzali MS, Donatelli RA, Vad VB. Pathophysiology of Injury to the Overhead-Throwing Athlete (W:) R Donatelli (red.): Sports-Specific Rehabilitation. Elsevier, Philadelphia; 2007

Ziv G., Lidor R. Vertical jump in female and male volleyball players: a review of observational and experimental studies. Scand J Med Sci Sports, 2010; 20(4): 556-568

\section{Corresponding author:}

\section{Mateusz Zubik}

Institute of Physical Education and Sports, AGH - University of Science and Technology,

Cracow, Poland.

E-mail:mzubik@agh.edu.pl 